\title{
Problems and Prospects of Small Scale Industries in Kakuri, Kaduna South L.G.A, Kaduna State, Nigeria
}

\author{
Mukhtar S. ${ }^{1, *}$, Ahmed A. ${ }^{2}$, Najib A. ${ }^{3}$ and Jibrin M. A. ${ }^{4}$ \\ ${ }^{1}$ Department of Geography, Federal University, Gashua, Yobe State, Nigeria \\ ${ }^{2,3}$ Department of Geography, Sule Lamido University, Kafin Hausa, Jigawa State, Nigeria \\ ${ }^{4}$ Department of Geography, Bayero University, Kano, Kano State, Nigeria \\ Corresponding Author: *smukhtar27.sm@gmail.com
}

\begin{abstract}
This study focuses on the problems and prospects of small scale industries in Kakuri, Kaduna south. The aim was achieved through the following specific objectives; identify the types of small scale industries, examine the problems of small scale industries and analyse the impact of small scale industries on the economic development of Kakuri industrial area. Data were collected through oral interviews and structural questionnaire administered to randomly sampled respondents. The study identified the major problems of small scale industries (SMIs) that hamper the growth of SMIs which includes; inadequate finance, shortage/ change in price of raw materials, poor infrastructures, etc. Based on the findings the study recommends that government should provide soft loans to small scale industries, adequate infrastructural facilities such as reliable power supply and roads. Government should also empower youth through training and financial assistance as a start-up capital.
\end{abstract}

Keywords: Small Scale Industry, Problems, Prospects, Economic development, Kakuri

\subsection{Introduction}

Manufacturing activities constitute only a small proportion of the economy of most developing countries. This is because agricultural activities dominate the economies of such countries as they are characterised by primary production. Where industries exist, they are mostly small scale and find it difficult to grow and reach to a level that can contribute meaningfully to the economic development of the countries (Adewunmi, 1970). Third world countries invariably lack the capacity to neither absorb nor even process raw materials into semi industrial goods. Hence, they seek external market to consume such semi-finished goods.

In many countries, small and medium scale industries have provided the system for encouraging indigenous entrepreneurship, enhancing greater employment opportunities per unit capital invested and aiding the development of local technology (Salisu, 2010). Small scale may sound small but actually play a very important role in the overall growth of an economy. Small scale industry (SMIs) can be characterized by the unique feature of labour intensiveness, simple management structure resulting from fusing ownership and management by one of few individuals. Thus, SMIs tend to strongly resolve the owner managers, rather than operate as a separate corporate entity. There is often greater subjectivity in decision making and prevalence of largely informal employer-employee relationship. They have very limited access to long term capital. The non-availability of fund often results in the non-adoption of modern technology and resort to modern processes (Shehu, 1989).

The importance of this industry increases due to the employment generating potentials it provides. It also provides a vehicle for reducing income disparities; develop a pool of skilled and semi-skilled workers as a basis for industrial expansion (Inang and Ukpong, 1993). 
The major and remarkable breakthrough in small scale industry came about through the Indigenization Decree of 1972 and later the Nigerian Enterprises promotion Act of 1977. These were the genuine attempt by the federal government to make sure that Nigerians play an active and worthwhile role in the development of small scale industries particularly in rural areas. This was in recognition of the role of small scale industries as the seed bed and training ground for entrepreneurship. According to Salisu (2010), despite the various importance of this sector to national and local development, significant attention has not been given by various administrations to the sector. As such small scale industries in Nigeria have been faced by a lot of problems such as difficulties in local source of raw material, capital inadequacy, poor managerial and technological knowhow as well as infrastructure deficiencies. Anyawu (2003), states that long term fund and working capital problem has pre-eminence in recognition of this and in order to address the problem, various effort and policies have to be put in place. To this end, the study concerns with the problems and prospects of small scale industries vis-à-vis to the economic growth and development in Kakuri industrial area, Kaduna south LGA, Kaduna state.

\subsection{Materials and Methods}

\subsection{Study area}

Kakuri industrial area is found in Kaduna south local government area of Kaduna state. It is situated in the Southwestern part of Kaduna metropolis which lies approximately between Latitude $10^{\circ} 33^{\prime \prime} \mathrm{N}$ of the equator and Longitude $7^{0} 21^{\prime \prime} \mathrm{E}$ of the Greenwich meridian of Kaduna state. It covers an area of about $30 \mathrm{~km}^{2}$ which extends from United Textile Limited (UNTL) to Railway Line of Kurmin Gwari. It is bounded to the north by Saint Gerald Catholic Hospital, Nassarawa State at the south, River Kaduna at the east and Peugeot Automobile Company of Nigeria (PAN) at the west (Kaduna state, 2012). The study area is one of the most industrialised towns in Kaduna State with different land use especially the residential part of Kakuri, which has grown to full capacity in size and population of about 77,374 according to the 2006 census (NPC, 2006). The area has a population structure of 1:1 ratio of male - female with large number of secondary school leavers, polytechnics and university graduates which provides a growing skilled labour force for the growing industries (NPC, 2006). A substantial part of the population engages in commerce, industrial labour and agriculture. The area is a home to several factories which includes Kaduna Textile Limited (KTL), Defence Industries Corporation (DIC) and Nigerian brewery (Iwalaiye, 2004). 


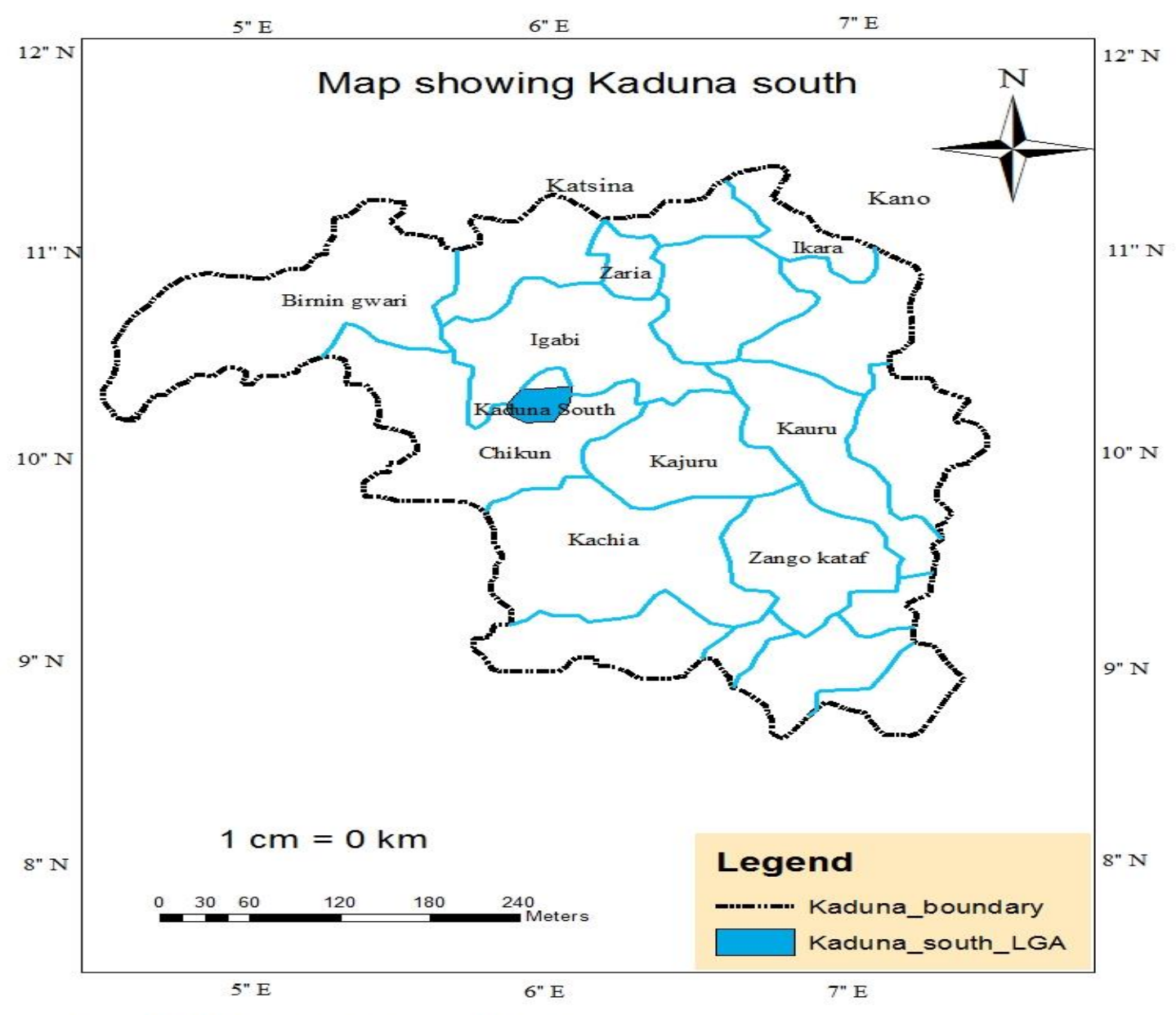

Source: Modified from admin map of Kaduna state

Figure 1: Map of Kaduna State showing the study area Source: Modified from Administrative Map of Kaduna State, 2012

The primary data was obtained through the use of questionnaire which was distributed randomly among small scale firms in the study area. It was administered to the entrepreneur of the SMIs in Kakuri industrial area to get information in the capital used to start the business, number of workers employed, types of small scale industry and various problems limiting the industries. Kakuri-Makera axis with the major road that connects the area was sampled which is characterised with both residential and industrial sites. The sample size of 100 SMIs operators was sampled for this study relative to the concentration of the industries. One questionnaire was given to each manager of the SMIs among the randomly selected industries.

Descriptive statistics was used in presenting the data which includes the statistical preparation tools such as tables and figures. Results were analysed using simple percentage.

\subsection{Results}

\subsection{Demographic characteristic of respondents}

Table 1 indicates that $90 \%$ of the respondents are males while $10 \%$ are females. This is tied to the reason that the African culture permits women to stay at home and take care of the family while the males who are considered the breadwinners of the family are set to cater for the family, thereby allowing the men to have the advantage of operating SMIs in the study area. Secondly, most of the activities are male oriented such as shoe making, carpentry and welding. The SMIs in the study area is also dominated by the working age group of $25-39$ years of age. This accounts for $62 \%$ of the sampled small scale industries. The result shows high rate of unemployment and under employment 
which is attributed to the increasing population which exceeds job opportunities. Consequently, allowing them to engage in other businesses that offer alternative source of employment.

Table 1: Demographic characteristic of respondents

\begin{tabular}{|c|c|c|}
\hline & Response & Percentage \\
\hline \multicolumn{3}{|l|}{ Sex } \\
\hline Male & 90 & 90 \\
\hline Female & 10 & 10 \\
\hline \multicolumn{3}{|l|}{ Age } \\
\hline$<20$ & - & - \\
\hline $21-24$ & 10 & 10 \\
\hline $25-29$ & 22 & 22 \\
\hline $30-34$ & 24 & 24 \\
\hline $35-39$ & 16 & 16 \\
\hline $40-44$ & 8 & 8 \\
\hline $45-49$ & 4 & 4 \\
\hline $50-54$ & 16 & 16 \\
\hline \multicolumn{3}{|c|}{ Educational Qualification } \\
\hline No Formal & - & - \\
\hline Primary & 12 & 12 \\
\hline Secondary & 54 & 54 \\
\hline Tertiary & 30 & 30 \\
\hline Others & 4 & 4 \\
\hline
\end{tabular}

Source: Field survey, 2012

The results from the Table 1 above also shows that small scale entrepreneurs in the study area have low educational qualifications with secondary and primary school leavers having $54 \%$ and $12 \%$ respectively with few having tertiary education $(30 \%)$. These points to the general low level of education of small scale industry operators which affects the production and efficient capacity of the industry in the area. Those with tertiary education are conceived to be those employed in the industries in Kakuri such as textile and brewery which was affected when these industries went on recession as such finds alternate means of survival.

\subsection{Characteristics of industries in Kakuri industrial area}

Capital is one of the factors of production which can be in form of cash to run the activities of the business or in form of machinery used in the production of a commodity in the industry. Majority of the respondents in the study area engage in small scale business that does not require much capital and labour. Table 2 indicates that shoe making and metal work accounts for $44 \%$ of the sampled SMIs while yoghurt making industry accounts for $2 \%$ only. Most of the respondents used to work in the industries located in Kakuri - Makera, but the recession of these industries made them to switch to other activities in order to earn a living. Consequently, this shows high level of unemployment and under employment in the State in general.

Table 2: Types of SMIs in Kakuri

\begin{tabular}{|l|l|l|}
\hline & Response & Percentage \\
\hline Shoe making & 22 & 22 \\
\hline Aluminium (glass) & 8 & 8 \\
\hline Bakery & 8 & 8 \\
\hline Pure water & 14 & 14 \\
\hline Yoghurt & 2 & 2 \\
\hline Block industry & 4 & 4 \\
\hline Carpentry & 4 & 4 \\
\hline Fashion & 16 & 16 \\
\hline Metal work & 22 & 22 \\
\hline \multicolumn{2}{|l}{ Source: Fied survey, } &
\end{tabular}

Source: Field survey, 2012

\subsection{Source of income}

Most of the small scale industries in the area are of low capital base because they are sourced from personal savings. Table 3 reveals that $94 \%$ of the SMIs source their capital or fund through personal savings by what is called "Asusu" in Hausa or "Adashi", while 6\% are supported by cooperative societies, relatives and banks. However, the crucial aspect of this analysis is the absence of 
government and private organisation in financing small scale industries in Kakuri. It can be deduced that one of the major problem of SMIs in the area is inadequate capital which hampers the growth of SMIs. In connection to the low level of education as revealed in Table 1, they are unable to obtain loan from banks and other financial institutions due to their inability to present adequate collateral.

Table 3: Source of income

\begin{tabular}{|l|l|l|}
\hline & Response & Percentage \\
\hline Personal saving & 94 & 94 \\
\hline Loan from bank & 2 & 2 \\
\hline Loan from government & - & - \\
\hline Loan from private organization & - & - \\
\hline Cooperative society & 2 & 2 \\
\hline Relatives & 2 & 2 \\
\hline
\end{tabular}

Source: Field survey, 2012

\subsection{Capital and labour base of SMIs}

SMIs in the study area start with a capital of less than 50,000 naira because they were generated through personal savings as revealed in Table 3 with $32 \%$ starting with capital base less than 50,000 naira, while very few SMIs start with capital of above 400,000 as seen in Table 4 as $14 \%$. The results show that the bottleneck faced by SMIs in the study area is nothing but lack of finance which hinders the growth of small scale industries. Labour, which is an essential factor of production, is also inadequate as shown in Table 4, with $68 \%$ employing less than 9 workers. This is acknowledged due to inadequate capital base that can only support a few number of workers in SMIs like shoe making and metal work industries. It is worth noting that SMIs in the study area are owned by single individuals as shown with $96 \%$ of SMIs sampled. This could be attributed to the mistrust people in the area have against each other.

Table 4: Capital and labour base of SMIs

\begin{tabular}{|c|c|c|}
\hline & Response & Percentage $(\%)$ \\
\hline \multicolumn{3}{|l|}{ Capital (Naira) } \\
\hline$<50,000$ & 32 & 32 \\
\hline $50,000-100,000$ & 18 & 18 \\
\hline $100,000-200,000$ & 12 & 12 \\
\hline $200,000-300,000$ & 12 & 12 \\
\hline $300,000-400,000$ & 12 & 12 \\
\hline $400,000-500,000$ & 6 & 6 \\
\hline $500,000-$ Above & 8 & 8 \\
\hline \multicolumn{3}{|l|}{ Number of workers } \\
\hline$<5$ & 40 & 40 \\
\hline $5-9$ & 28 & 28 \\
\hline $10-14$ & 18 & 18 \\
\hline $15-19$ & 10 & 10 \\
\hline $20-$ above & 4 & 4 \\
\hline \multicolumn{3}{|l|}{ Ownership of SMIs } \\
\hline Sole proprietor & 96 & 96 \\
\hline Joint - family & 2 & 2 \\
\hline Partnership & 2 & 2 \\
\hline Public & - & - \\
\hline
\end{tabular}

Source: Field survey, 2012

\subsection{The importance and problems of SMIs in Kakuri}

Despite the inadequate labour force in the SMIs in the study area, the SMIs have proven to provide employment for the few that were affected by the recession that occurred to the industries in the area. Also, products from the small scale industries in the area are consumed locally with 56\% response while $36 \%$ and $6 \%$ reached both national and international market respectively as shown in Table 5. This is also attributed to insufficient capital, low level of education and technology which hinders the growth of SMIs to producing for higher markets.

Small scale industries are confronted with some problems that hamper their growth. Majority of the respondents complained of various problems among which inadequate finance ranks high with $64 \%$. 
For an industry to start and flourish well it needs enough capital base to accommodate other factors such as labour, raw materials, etc. and when it is inadequate, the rest suffers it. Also, $14 \%$ of the respondents complained of dwindling price of raw materials which varies timely as a result of market fluctuation. Infrastructures such as electricity, roads and water are inadequate in the area. These infrastructures especially electricity serve as source of power to most industries both operating at small and large scale. The poor nature of these infrastructures has great influence on the cost of running the SMIs and caused some to go into recession. Other problems include poor management, government policy and decline in product which accounts for $10 \%$ of the respondents as shown in Table 5.

Table 5 also shows that $34 \%$ of small scale operators in the study area believed that their industries provides goods for the community and Kaduna State in general while $32 \%$ feel that their industry is a good training ground for them. Also, 30\% of the respondents are of the belief that the industries have reduced unemployment in the area especially for semi- skilled and unskilled labour (Salisu, 2010). Due to the low level of education in the area people in the area engage in other business like shoe making, welding, and carpentry and tailoring.

Table 5: The importance and problems of SMIs in Kakuri

\begin{tabular}{|l|l|l|}
\hline \multicolumn{2}{|l|}{ Response } & Percentage \\
\hline Market extent & 56 & 56 \\
\hline Local & 38 & 38 \\
\hline National & 6 & 6 \\
\hline International & \multicolumn{2}{l|}{} \\
\hline Major problems affecting SMIs & 64 & 64 \\
\hline Lack of finance & 14 & 14 \\
\hline Low price of raw material & 12 & 12 \\
\hline Poor infrastructure & - & - \\
\hline Inadequate labour & 4 & 4 \\
\hline Poor management & 2 & 2 \\
\hline Government policy & - & - \\
\hline Attitude of individuals & 4 & 4 \\
\hline Decline in product & \multicolumn{2}{|l|}{} \\
\hline Contribution of SMIs to the area & 30 & 30 \\
\hline Reduced unemployment & 4 & 4 \\
\hline Source of innovation & 34 & 34 \\
\hline Provides local goods & 32 & 32 \\
\hline Training ground & \multicolumn{2}{|l|}{} \\
\hline Source: Field survey, 2012 & \\
\hline
\end{tabular}

Source: Field survey, 2012

\subsection{Conclusion}

In general, Nigerian small scale industries make valuable contribution to the economy which this study has also shown. The observed weak performance of small scale industries occasioned by lingering constraints should however serve as lesson for our policy makers to fashion out strategy that will be sufficient and responsive to the small scale industries. However, this study has shown that small scale industries by their nature have insufficient access to formal financial institution and as a result rely much more on their personal savings and informal financial institution for their capital investment. It has also been observed that some government policies may be harmful to the small sale industries such as lower tariff on importation which can increase competition with foreign goods imported. Based on the findings of this study, policies formulated by government should be communicated to people via town hall meetings, workshops, seminars, media and publications. Adequate training like that of the Subsidy Reinvestment and empowerment program on (SURE-P) which was initiated by Federal Government of Nigeria should be established. This will serve as a better avenue to train small scale industrialist before they kick-start their businesses. Banks should provide soft loans to aid small scale industries. More so, infrastructural facilities should be rehabilitated by government especially roads in order to boost industrial activities. Electricity should be made available and affordable in order to provide high level productivity. Similarly, local goods consumption should be encouraged while importation should be discouraged. 


\section{References}

Adewunmi, J. O. (1970). Analysis of major industries in Zaria. Unpublished B.A thesis of Geography Department, ABU.

Anyawu, C. M. (2003). The role of Central Bank of Nigeria in Enterprises financing. CBN Economic and Financial Review, 24 (1).

Edwin, U. (2009). Analysis of Locational factors of Small Scale Industries in Samaru, Sabon Gari $L G A$. Geography Department, ABU Zaria.

Inang, E. E. and Ukpong, G.E. (1993). A review of Small Scale Enterprises credit delivery in Nigeria. Abuja: CBN occasional paper research Department.

Iwalaiye, E. (2004). Causes of mortality in kakuri industrial area. Unpublished project of Geography Department, ABU, Zaria.

Kaduna state. (2012). Retrieved 12 09, 2012, from Galleria media Limited: http://www.nigeriagalleria.com/Nigeria/States_Nigeria/Kaduna/Kaduna_State.html

NCI. (2002). Small and Medium Scale Enterprises and funding in Nigeria. National Council For Industries.

NPC. (2006). National population census report. National Population Commission.

Olorunsho, J. A. (2001). Industrial Financing in Nigeria. Some institutional arrangements. CBN Economic and Financing Review.

Salami, A. T. (2003). Guidelines and Stakeholders responsibilities in SMEs. CBN Economic and financial review.

Salisu, A. (2010). Problems and Prospects of Small Scale Industries. Kaduna south: Unpublished project of Geography Department, ABU.

Shehu, S. (1989). Small Scaale Industries in Nigeria. A case study of design media. Kaduna: Unpublished project of Economic Department, ABU.

Sule, E. K. (1986). Small Scale in Nigeria. Concepts, appraisal of Government policies and suggested solutions to identified problems. CBN Economic and financial review.

Udechukwu, F. N. (2003). Survey of Small and Medium Scale Enterprises and their potentials. African ExpressBank PLC.

Worldbank. (1995). Private sector development in low income countries. Washington DC: World Bank. 